\title{
Direct Primary Care: Practice Distribution and Cost Across the Nation
}

\author{
Philip M. Eskew, DO, JD, MBA, and Kathleen Klink, MD
}

Direct primary care (DPC) is an emerging practice alternative that (1) eliminates traditional third-party feefor-service billing and (2) charges patients a periodic fee for primary care services. We describe the DPC model by identifying DPC practices across the United States; distinguish it from other practice arrangements, such as the "concierge" practice; and describe the model's pricing using data compiled from existing DPC practices across the United States. Lower price points and a broad distribution of DPC practices were confirmed, but data about quality are lacking. (J Am Board Fam Med 2015;28:793-801.)

Keywords: Fees and Charges, Primary Health Care, Health Care Costs, Health Services Accessibility, Patient-Centered Care

Direct primary care (DPC) is a growing model used by family physicians and other primary care specialties aimed at delivering quality care at an affordable price. The model emphasizes ongoing and preventive care services, and third-party fee-for-service payments are abandoned. Instead, a periodic (usually monthly) fee is paid to the DPC physician to better reflect the ongoing patient relationship. The affordability of the monthly fee and the high patient and physician satisfaction have garnered national media attention from many news sources including Time, ${ }^{1}$ Forbes, ${ }^{2}$ the New York Times, ${ }^{3}$ and The Hill. ${ }^{4}$ This article clarifies terminology in part by analyzing practice self-descriptions, describes Medicare "opt out" and "split" practice data, provides an overview of the periodic fees practices have made publicly available on their websites, and presents other raw practice data in an effort to offer a national snapshot of the growing DPC movement.

\section{DPC Terminology and Background}

For the purposes of inclusion in our study, a DPC practice must be a primary care practice that (1)

This article was externally peer reviewed.

Submitted 9 December 2014; revised 5 May 2015; accepted 11 May 2015.

From The Robert Graham Center, Washington, DC.

Funding: none.

Conflict of interest: none declared.

Corresponding author: Philip M. Eskew, DO, JD, MBA, Frontier Direct Primary Care, 2005 Warren Avenue, Cheyenne, WY 82001 (E-mail: philsq@gmail.com). charges a periodic fee for services, (2) does not bill any third parties on a fee-for-service basis, and (3) any per-visit charges are less than the monthly equivalent of the periodic fee. ${ }^{5}$ This definition represents a comprehensive legal interpretation of 14 state laws passed to clarify DPC "business of insurance" regulatory questions and language from the Affordable Care Act describing mechanisms for DPC practices to participate in the insurance exchanges with "wraparound" insurance products. DPC practices often are compared with other models that charge a periodic fee, most commonly the concierge model. Price differences between the models are usually acknowledged, but price is absent from any legislative or regulatory definition of DPC.

Practices' periodic fees have been described using many terms, including retainer, membership, concierge, hybrid, split, direct pay, and direct primary care. Any group that charges patients on a periodic basis might be described using 1 or more of these adjectives. The terminology continues to evolve, but direct primary care and concierge are the terms that have taken on the greatest meaning. The most well-known concierge practices, such as MDVIP or $\mathrm{MD},{ }^{2}$ continue to bill third parties in the traditional fee-for-service fashion in addition to the periodic fee, a method many describe as "double dipping." By contrast, DPC practices rely on the periodic fee to finance the practice without any third-party fee-for-service payments. Some prac- 
tices treat one cohort of patients in the DPC model and another cohort in the traditional third-party fee-for-service model; we refer to these as "split practices." Medicare regulations prohibit physicians from charging DPC patients for covered primary care services via the DPC model, so many DPC physicians who would like to make their services available to the Medicare population decide to "opt out" of Medicare so that they may privately contract with Medicare patients.

DPC practices claim to reduce overhead by more than $40 \%$ by eliminating administrative staff resources associated with third-party billing, resulting in lower price points for patients. ${ }^{7}$ DPC physicians cite 3 key practice improvements: (1) increased availability and, therefore, access; (2) more time for each patient encounter, leading to improved quality; and (3) lower overhead costs. ${ }^{8} \mathrm{~Pa}$ tients may usually join without regard to their insurance or socioeconomic status since practices often "opt out" of Medicare and do not sign traditional contracts with private insurance companies or Medicaid. For non-primary care services, DPC patients rely on a variety of options, ranging from the usage of high-deductible health insurance plans or "wraparound" insurance plans designed to cover everything except primary care (as specifically authorized by the ACA; discussed below) to traditional employer-sponsored insurance, Medicare, Medicaid, or ACA-exempted "health-sharing" ministries. ${ }^{9}$ Uninsured patients who need traditionally expensive nonemergent procedures such as a colonoscopy or magnetic resonance imaging often benefit from the DPC physicians' efforts to negotiate lower "cash pay" prices on their behalf, and depending on the DPC practice, some radiologic testing might be included at no additional cost. $^{10}$

\section{Methods}

A thorough literature search demonstrated a paucity of data available to describe the DPC practice model. Studies related to DPC were located using the following search terms in PubMed and Google: direct primary care, retainer medicine, membership medicine, concierge medicine, and boutique medicine. The phrase "direct primary care" yielded only 3 relevant results in PubMed. We conducted a review of information publicly available on DPC practices' websites that met our 3-part definition in an effort to describe the number of practices adopting the model, the terminology advertised (self-description), and their distribution. We gathered information about the size of practices, the providers involved, and costs to provide a broad overview of the current state of DPC in the United States.

DPC practices were identified through a review of literature, practice listings from databases in the 2 states that require DPC practice registration and publication (Washington ${ }^{11}$ and Oregon ${ }^{12}$ ), and meeting agendas of the Direct Primary Care Coalition $^{13}$ and Direct Primary Care Summit ${ }^{14}$ held in June 2014. We included all practices that met the 3-part definition of DPC (identified via the above-described methods) either exclusively as a "pure" DPC practice or as part of a split practice model.

The following data were collected: number of physicians in the practice, number of nonphysician clinicians, lowest periodic (monthly) fee for patients older than age 29, highest periodic (monthly) fee for patients older than age 29, any per-visit fee, any enrollment fee, Medicare opt-out status, whether the practice was split, and the terminology the practice used to advertise (self-describe) its membership model.

An estimation of the total average monthly cost of care was obtained by averaging the monthly low and high costs, assuming patients visited the practice an average of 4 times per year, ${ }^{15}$ and amortizing the first year's enrollment fee over a 12-month time period via the following formula:

$$
\begin{aligned}
& {[(\text { Monthly low fee }+ \text { Monthly high fee }) / 2]} \\
& +[\text { Per-visit fee } \times 4 / 12] \\
& \quad+[\text { Enrollment fee/12] }
\end{aligned}
$$

\section{Results}

DPC practices tend to fall naturally into 1 of 3 cohorts: (1) small and independent practices with varying levels of network affiliation, (2) split practices that are either independent or often entirely dependent on a network for their DPC patients, or (3) larger practices that tend to employ physicians and grow rapidly by marketing themselves directly to large employers. Many other arrangements certainly exist; of note, one hospital offers an "Affordable Access" DPC program at $\$ 30$ per month, ${ }^{16}$ 
Figure 1. Monthly costs to patients. DPC, direct primary care.

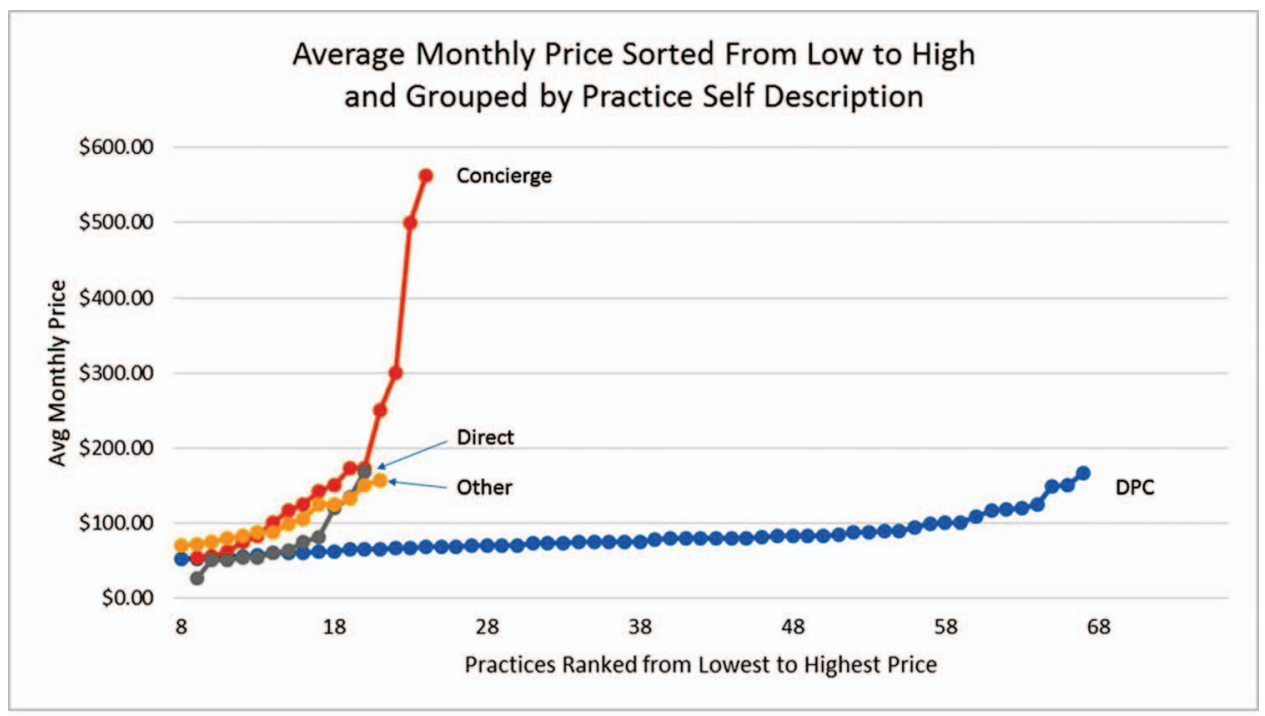

and even some urgent care chains ${ }^{17}$ are offering DPC options.

Networks may be used by providers for a variety of different purposes, from learning about the model to recruiting/enrolling patients (especially from large employers), sharing group purchasing discounts, and sharing electronic medical records and membership management platforms. Examples of networks are available in the full practice listing in the Appendix. Because of the variety of network options and lack of transparency regarding practice participation in networks, precise data could not be aggregated from this website review.

We located 141 practices with 273 locations spanning 39 states (see Figure 3 and the Appendix). Practices with $\leq 4$ providers comprised $93.2 \%$ of those included in the study. Of the 141 practices, 87 disclosed enough information for us to determine whether they were "pure" or "split" (73 [83.9\%] were pure and 14 [16.1\%] were split), and 84 disclosed enough information for us to determine whether they had opted out or were accepting Medicare (65 [77.4\%] opted out and 19 [22.6\%] accepted Medicare). Of the 65 practices that opted out of Medicare, 1 operated in a split fashion. A practice self-description was recorded for every practice in the study. The following terms were used: DPC by 75 practices (53.2\%), concierge by 21 (14.9\%), direct by 17 (12.1\%), and other by 22 $(19.6 \%)$.
Of the 141 practices identified, $116(82 \%)$ have cost information available online. When these 116 practices are analyzed, the average monthly cost to the patient is $\$ 93.26$ (median monthly cost, $\$ 75.00$; range, $\$ 26.67$ to $\$ 562.50$ per month). While all the practices included in our study met our definition of DPC, not all the practices used the phrase "direct primary care" to self-describe their practice model. Seventy-five of the studied practices (53\%) referred to their model using the phrase "direct primary care." Practices that used the phrase DPC on average charged a lower fee than practices that used the term concierge to describe their model: $\$ 77.38$ compared with $\$ 182.76$, respectively. Of 116 practices with available price information, 28 (24\%) charged a per-visit fee, and the average pervisit charge among this group was $\$ 15.59$ (range, $\$ 5$ to $\$ 35$ ). Thirty-six of these 116 practices charged a one-time initial enrollment fee, and the average enrollment fee among this group was \$78.39 (range, \$29 to \$300). Figures 1 and 2 present monthly cost data.

Most DPC practices are young and small and thus lack sufficient quality and cost data to assess outcomes. The larger practices (especially Qliance, Iora Health, and Paladina) are known to have patient panels as large as 40,000 and routinely grow at faster rates by marketing themselves to large employers looking to purchase DPC plans for their employees. Most DPC practices are too small or 
Figure 2. Average monthly price (sorted from low to high) and grouped by practice self-description.

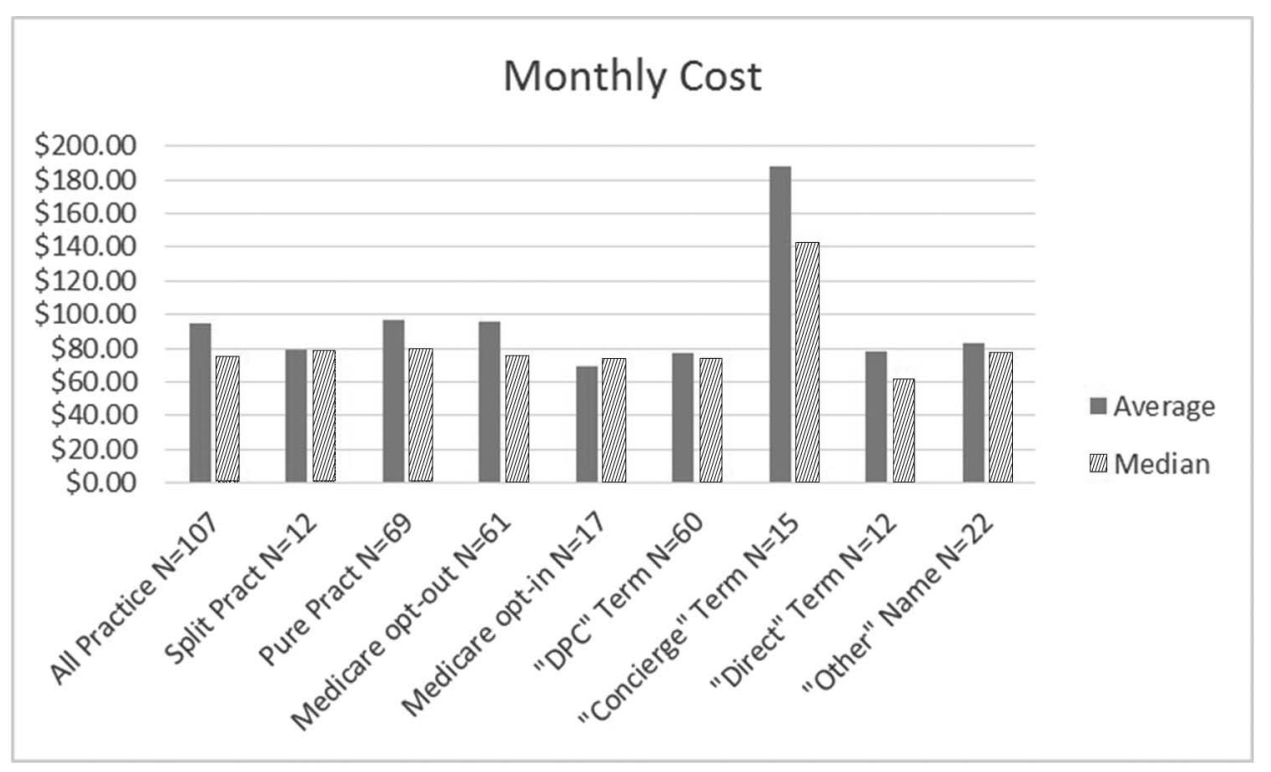

young to have collected quality outcomes data, but we identified 2 mature practices that have compiled information: Access Health Care and Qliance. ${ }^{18}$

Access Health Care has been deemed a Cardiovascular Center of Excellence since 2009 by the Consortium for Southeastern Hypertension Control. ${ }^{19}$ An unpublished study performed by the University of North Carolina School of Medicine and North Carolina State University MBA students demonstrated that the group's DPC patients spend $85 \%$ less out of pocket for their total cost of care compared with the same level and amount of care in a traditional setting. Patients receive an average of 35 minutes per visit (compared with 8 minutes in the traditional model). ${ }^{20}$

Qliance is the first example of a corporate, multisite DPC model. ${ }^{21}$ Internal data from the group demonstrates that Qliance patients have a $>50 \%$ reduction in emergency department visits, specialist visits, advance radiologic testing, and surgical procedures than traditional practices. ${ }^{22,23}$ The only measure of increased utilization is the number of primary care visits, which more than doubled from an average of 2 to an average of 4 per year during the reporting period. ${ }^{23}$ The logical inference is one that primary care advocates have insisted is true in every health system: As the utilization of low-cost comprehensive primary care increases, the need for high-cost emergency and specialty services decreases.
Though Qliance initially enrolled individual patients, currently employers (such as Expedia) contract with Qliance to pay membership fees as an employee benefit. Qliance recently enrolled an additional 20,000 patients via a Medicaid managed care contract, where Medicaid simply pays the membership fee on behalf of the patients as part of a shared savings program. ${ }^{23}$ Another 5,000 patients signed up with Qliance via the insurance exchange. This was made possible by a provision of the Affordable Care Act that permits DPC practices to be offered in a bundled fashion in the insurance exchanges when paired with a wraparound insurance policy. $^{24}$

The Affordable Care Act contains a provision in Section 10104 stating that the Department of Health and Human Services "shall permit a qualified health plan to provide coverage through a qualified direct primary care medical home plan that meets criteria established by the Secretary. .."24; the Department of Health and Human Services later described a direct primary care medical home plan as "an arrangement where a fee is paid by an individual, or on behalf of an individual, directly to a medical home for primary care services, consistent with the program established in Washington." ${ }^{25}$ This ACA provision and similar topics are discussed in detail in the article providing a legal and regulatory review of DPC by Eskew. ${ }^{5}$ 


\section{Direct Primary Care Practice Distribution}

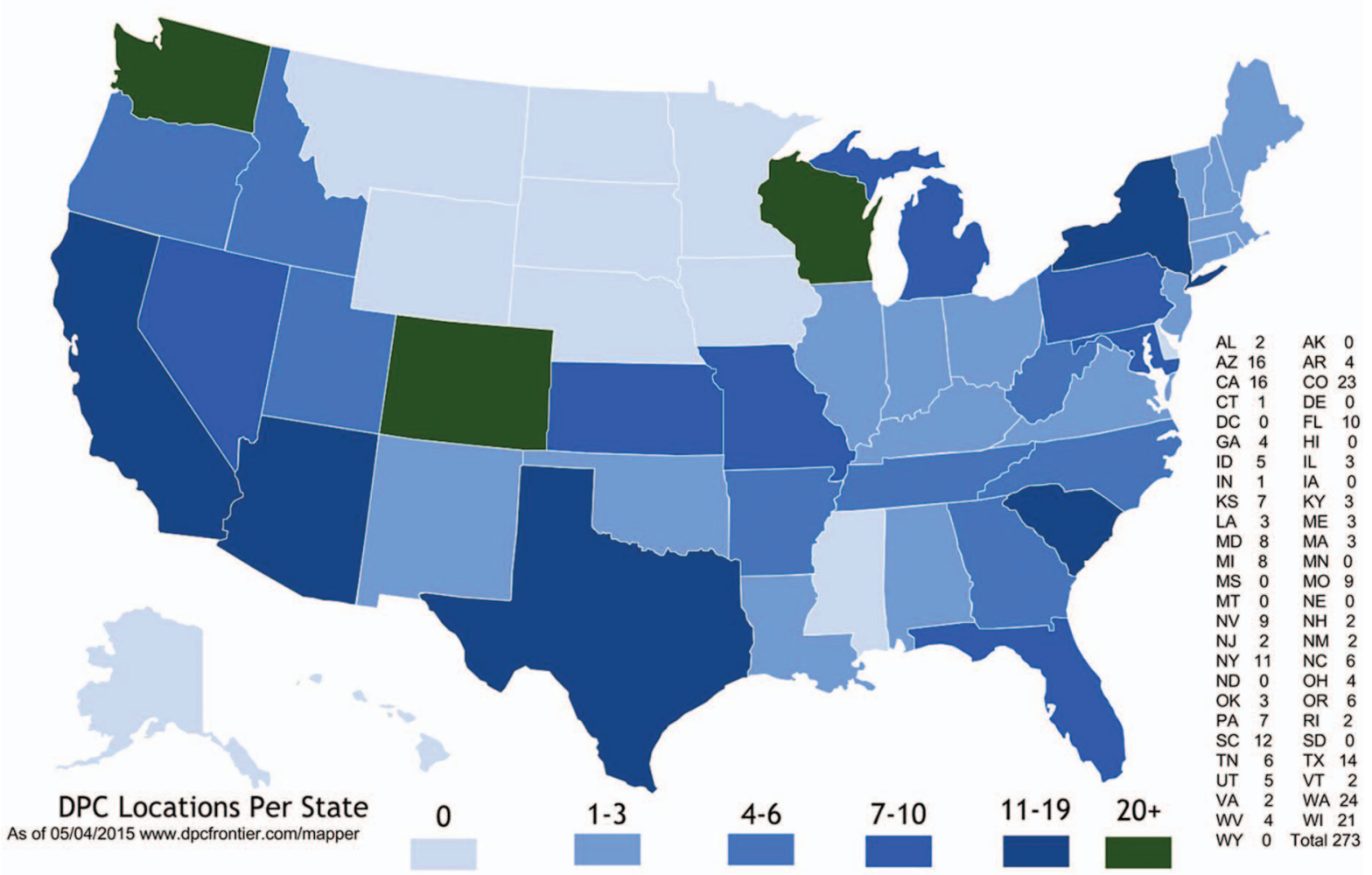

\section{Discussion}

A medical literature search did not identify a consistent or consensus definition of the DPC model; thus we relied on a detailed legal analysis to articulate the 3-part definition of DPC used for this study. Prior editorial publications often used terminology indiscriminately, contributing to broad misperceptions about the nuances among DPC, concierge, and other periodic fee models. A narrow majority of practices in the study self-describe as DPC. Practices are certainly free to advertise in any manner they chose, but this inconsistency in terminology certainly contributes to confusion on the part of patients and policymakers.

Selection of geographic location seems to be fairly flexible. Practices are located in both urban and rural settings across 39 states. The exact locations of DPC practices that met our definition are continuously updated online in the DPC Mapper. ${ }^{26}$ Earlier studies demonstrated that each state's regulatory environment is different, and this may play a role in why some states have more DPC practices than others. ${ }^{27}$ Physicians wishing to start a DPC practice may need to spend time understanding the legal and regulatory requirements at both the state and federal levels that will affect the practice. ${ }^{5}$

We found the public perception of the term concierge as having higher prices holds true. Selfdescribed DPC practices charged a lower average monthly fee (\$77.38) than DPC practices that selfdescribed as concierge (\$182.76). Concierge practices such as MDVIP and $\mathrm{MD}^{2}$ have listed average periodic (monthly) fees of $\$ 137.50$ and $\$ 2083.33$, respectively; these periodic fees are billed in addition to standard fee-for-service office visit and procedural charges that would be encountered in any traditional medical practice. ${ }^{28}$

The third-party fee-for-service payment system compensates physicians on a per-unit basis. Physicians billing for a small number of units at high prices (common in specialties that perform expensive procedures) may find that the overhead cost associated with processing each claim is acceptable. In an outpatient-focused practice where procedures 
are less frequent and/or less expensive, DPC physicians have found that the overhead associated with collecting fees on a per-unit basis is too high to be worth the effort. The administrative efficiencies gained by abandoning third-party fee-for-service overhead are often cited as one of the chief reasons that DPC is offered at minimal cost to the patient. We anticipated that the presumed lower overhead costs in "pure" DPC practices would result in lower periodic fees when "pure" practices were compared with "split" practices that should continue to carry a higher overhead burden, but there was no significant difference in periodic fees between the 2 groups.

Limitations in calculating the monthly costs include (1) complicated price structures (some practices offer family discounts, employer discounts, and other pricing options that could not be easily incorporated into this formula); (2) a lack of price transparency on many practice websites; and (3) scope of practice variance (items covered by the membership fee vary widely). Some practices provide some medications, laboratory testing, and radiologic testing without additional costs. The second most expensive DPC practice included in our website review includes hospitalist (inpatient) services without an additional physician fee. ${ }^{29}$

Future studies should focus on obtaining data supporting the quality claims made by DPC physicians and patients. DPC practices typically advertise open and continuous patient access to the physician and, according to preliminary, proprietary, and unpublished practice-level data, may be associated with better health outcomes with fewer hospitalizations, fewer emergency department visits, fewer specialist visits, and less radiologic testing. Proponents of DPC practices regularly refer to these benefits, but if the model is to be more widely adopted, more data about DPC practices are needed to document potential improvements. DPC practices should be described using accurate and consistent terminology to minimize confusion, and continued efforts at price transparency at all levels are recommended.

\section{References}

1. Von Drehle D. Medicine is about to get personal. Time, December 22, 2014. Available from: http:// time.com/3643841/medicine-gets-personal/. Accessed April 28, 2015.

2. Hixon T. Healthcare costs: low-hanging fruit. Forbes, April 4, 2014. Available from: http://www.forbes.com/ sites/toddhixon/2014/04/04/healthcare-costs-low-hanging-fruit/. Accessed April 28, 2015.

3. Japsen B. More care up front for $\$ 54$ a month. New York Times, May 21, 2012. Available from: http:// www.nytimes.com/2012/05/22/health/direct-primarycare-providers-extend-concierge-services.html?_r=1. Accessed April 28, 2015.

4. Engelhard C. Is direct primary care part of the solution or part of the problem? The Hill, October 13, 2014. Available from: http://thehill.com/blogs/pundits-blog/ healthcare/220527-is-direct-primary-care-part-of-thesolution-or-part-of-the. Accessed April 28, 2015.

5. Eskew P. Direct primary care legal and regulatory review of an emerging practice model; citing interpretations of the Wash. Rev. Code $\$ 48.150 .010$ (2007), Louisiana Revised Statutes $\$ \$ 37: 1360.81$ through 1360.91, The Patient Protection and Affordable Care Act, Pub. L. No. 11-148, 124 Stat. 119, \$ 10104 (Mar. 23, 2010), Treatment of Direct Primary Care Medical Home, 76 Fed. Reg. 41900 (July 15, 2011) (amending section 1301(a)(3) of the Affordable Care Act), Treatment of Direct Primary Care Medical Home, 77 Fed. Reg. 18423 (Mar. 27, 2012), ORS $\$ 735.500,735.510$ (2011), W. Va. Code $\$ 16-2 J-1$ (2013), Utah Code \$ 31A-4-106.5. Medical retainer agreements, Arizona Revised Statutes $\$ 20$ 123, Michigan Compiled Laws \$ 500.129, Miss. Code Ann. \$ 83-1-101, Idaho Code \$\$ 39-9201 to 39-9208, Oklahoma Statutes Title 36 \$ 4604. Available from: http://c.ymcdn.com/sites/www.aclm.org/ resource/collection/398353CC-E8B1-42EB-B6E70E725F1C4C42/10_Eskew_Phillip-nocover.pdf?. Accessed October 13, 2015.

6. Portman R, Romanow K. Concierge medicine: legal issues, ethical dilemmas, and policy challenges. J Health Life Sci Law 2008;1:1, 3-38.

7. Forrest B. Breaking even on four visits per day. Fam Pract Manag 2007;14:19-24.

8. Wu WN, Bliss G, Bliss EB, Green LA. Practice profile a direct primary care medical home: the Qliance experience. Health Aff (Millwood) 2010;29: 959-62.

9. Internal Revenue Bulletin 2013-39. T.D. 9632. Shared responsibility payment for not maintaining minimum essential coverage. September 23, 2013. Available at: http://www.irs.gov/irb/2013-39_IRB/ ar09.html. Accessed April 28, 2015.

10. Twiddy D. Practice transformation: taking the direct primary care route. Fam Pract Manag 2014; 21:10-5.

11. Washington State Office of the Insurance Commissioner. Direct health care providers. Available from: http://www.insurance.wa.gov/your-insurance/healthinsurance/cant-afford/health-plans/direct-health-carepractices/direct-health-care-practice-list.html. Accessed October 13, 2015.

12. Oregon Department of Consumer and Business Services. Medical retainer practice registrants. Available 
from: http://www4.cbs.state.or.us/ex/imd/reports/rpt/ index.cfm?ProgID=REG8105. Accessed April 28, 2015.

13. Direct Primary Care Coalition [homepage]. Available from: http://www.dpcare.org. Accessed April 28, 2015.

14. Family Medicine Education Consortium. Direct primary care national summit [homepage]. Available from: http://www.fmec.net/dpc.htm. Accessed April 28, 2015.

15. Fam Med Education Consortium, Direct Primary Care National Summit, Presentations by Garrison Bliss of Qliance entitled "Corporate Multi-Site DPC".

16. Snoqualmie Valley Hospital. Affordable access program [homepage]. Available from: http:// www.snoqualmiehospital.org/services/affordableaccess-program/. Accessed April 28, 2015.

17. MD Stat Urgent Care. Medical membership. Available from: http://mdstaturgentcare.com/ medical-membership/. Accessed April 28, 2015.

18. Family Medicine Education Consortium. Direct Primary Care Summit, June 20-21, 2014, Arlington, VA, agenda. Available from: http://www. fmec.net/numo/extensions/wysiwyg/uploads/ u.11.DPC2014Schedule_6.9.14.pdf. Accessed April 28, 2015.

19. Consortium for Southeastern Hypertension Control. Centers of excellence. Available from: http://www. cosehc.org/V2/Centers.aspx. Accessed April 28, 2015.

20. Forrest B. Rise of the direct primary care solution: how a direct care model can allow independent practices to thrive. Presented at the Family Medicine Education Consortium Direct Primary Care Summit, Arlington, VA, June 20, 2014.

21. Wu WN, Bliss G, Bliss EB, Green LA. Practice profile. A direct primary care medical home: the Qliance experience. Health Aff (Millwood) 2010; 29:959-62.

22. Page L. The rise and further rise of concierge medicine. BMJ 2013;347:f6465.

23. Bliss G, Bliss E. Qliance corporate multi-site DPC model. Presented at the Family Medicine Education Consortium Direct Primary Care Summit, Arlington, VA, June 20, 2014.

24. Patient Protection and Affordable Care Act. PL no. 11-148, 124 Stat. 119, \$10104 (March 23, 2010).

25. Treatment of direct primary care medical home. 76 Fed. Reg. 41900 (July 15, 2011) (amending section 1301(a)(3) of the Affordable Care Act).

26. Eskew P, DPC Frontier. DPC mapper. Available from: www.dpcfrontier.com/mapper. Accessed April 28, 2015.

27. Eskew P. Direct primary care membership medicine. W V Med J 2014;110:8-11.

28. Leonard D. Is concierge medicine the future of health care? Bloomberg BusinessWeek, November 29, 2012.
Available from: http://www.businessweek.com/printer/ articles/84322-is-concierge-medicine-the-future-ofhealth-care. Accessed April 28, 2015.

29. The Knope Clinic. FAQ. Available from: http:// www.conciergemedicinemd.com/for-patients/faq/. Accessed April 28, 2015.

30. Chase D. On retainer: direct primary care practices bypass insurance. Oakland and Sacramento: California Healthcare Foundation; 2013. Available from: http:// www.chcf.org/publications/2013/04/retainer-directprimary-care. Accessed September 18, 2015.

31. Flood J. Direct primary care in Louisiana. A white paper for Louisiana lawmakers and healthcare stakeholders in support of Senate bill 516. Baton Rouge (LA): Flood International Consulting Agency; 2014. Available from: http://www.floodconsulting.com/pdf/ Direct\%20Primary\%20Care\%20in\%20La_Support\% 20for\%20SB516.pdf. Accessed April 28, 2015.

32. McCorry D. Direct primary care: an innovative alternative to conventional health insurance. Backgrounder 2014;(2939):1-13. Available from: http://thf_media.s3.amazonaws.com/2014/pdf/ BG2939.pdf. Accessed April 28, 2015.

33. MedLion Direct Primary Care. Employers. Available from: http://medlion.com/home/solutions-for-you/ employers/. Accessed April 28, 2015.

\section{Appendix}

\section{Listing of DPC Practices}

121MD

Access Direct Care

Access Health care (Albenberg)

Access Health care (Forrest) ${ }^{* *}$

Access MD

Access Medical Home

Access Medicine

Akin Family Medical Care

Alliance Concierge Care

Alonso, Lynn, MD

AMG Medical Group*

Anchor Medical Clinic

Appleton Clinics

Assurance Healthcare \& Counseling Center

AtlasMD**

Austin Osteopathic Family Medicine

Balance Health

Baskin Clinic

Belleview Medical Partners

Birdwell Ferris Clinic

Bluegrass Family Wellness

Bluesky Direct

Bridge City Family Medicine

Broderick, Dawn, MD

Brooks Family Care 
Care Only

Carlson, Rhonda, MD

Ciampi Family Practice

Compass Health care

Consolaré Personal Physician Services

Crescent Medical

Criscenzo, Donna, MD

Cunningham, Alicia, MD

Davinci Medical DPC

DC Clinic Northwest Arkansas

Diamond Luxury Health Care

Direct Access Family Care

Direct Doctors Inc.

Direct MD Austin

Direct Patient Services

Direct Primary Care of Austin

Direct Primary Care Carolinas

Direct Primary Care Clinics

DirectcareMD (Heritage FM)

Direct Medical Care

The Doc Shoppe

Dr. Rob Lamberts, LLC

Epiphany Health

Evolve Medical Clinics

Exceptional Health Care

Faith Family Clinic

Family Health Center Direct

Fields, Robert, MD

Flat Rock Health

Forest Direct Primary Care

Free Market Physician

Freedom Family Practice

Functional Family Medicine

Furlow, John, MD

Gold Direct Care

Good MD

GracePointe Health Care

Green Medicine

Guardian Family Care

Hannon \& Maltz

Health Access Rhode Island ${ }^{* *}$

A Heartbeat Away Clinic

Henjum, Philip, MD

Hendler, Jared, MD

Highland Urgent Care \& Family Medicine

Icon Pediatrics

Independent MD

Innova Medical Care

Insight Primary Care

Institute for Medical Wellness

Integrative Family Medicine Asheville
Iora Health*

Island Direct Care

Ivers, Greta, MD, MPH

Izbiki Family Medicine

Kaysville Clinic Family Med

The Knope Clinic

Lacamas Medical Group

Landsdale, Thomas, MD

Live Active Primary Care

Lutz, Kevin, MD

Marable (Sublime) Health care

Megunticook Family Medicine

MDStat Urgent Care

Medical Access USA

Medlion**

Melioria Family Medicine

Morningstar Family Health Center

MyDoc Personal Physician Service

NeuCare Family Medicine

Nextera Health Care

Northwest Direct Care

Nostalgia Family Medicine

Oasis Family Medicine

One Focus Medical

Osteopathic Center Family Medicine

Our Lady of Hope Clinic

Pacific Direct Care

Paladina Health*

Palmetto Proactive Health care*

Patient Centered Physicians Group

PeaceHealth Medical Group

PeakMed Primary Care

Personal Family Physicians

Prairie Health \& Wellness

Premier Personal Health Care

PrimaraCare**

Primary Care One

Priority Health Family Medicine

Priority Physicians

ProPartnersMD Direct

Qliance* $^{*}$

R Health Connect

Revolutionary Health Services

Rio Picos Family Practice

River Rock Medical Clinic

Roark Family Health

Rockville Concierge Doctors

Roth Medical Clinic

Salud Optima Direct

Samuel, Richard, MD

Sanctuary Medical Care \& Cons 
Scotland Family Medicine

Seattle Medical Associates

Seattle Premier Health

Snoqualmie Ridge Medical Clinic

Solstice Health

SparkMD

Treasure Valley Family Med

Unorthodoc

Vantage Physicians

The Village Doctor

Washington Park Direct Care

Yapha Physician Services

Wells Medical Clinic

Zenith Direct Care

${ }^{*}$ Large ( $>5$ providers)

${ }^{* *}$ Network total $=141$.

A white article by Dave Chase, ${ }^{31}$ written for the California Health Care Foundation, highlighted Iora Health, MedLion, Paladina Health, and White Glove Health. Similar helpful white articles have been published by Jarrett Flood ${ }^{32}$ for the Louisiana Lawmakers and by Daniel Mc-
Corry $^{33}$ for the Heritage Foundation. Iora Health mainly operates employer-focused DPC practices often providing services for union groups using physicians paired with health coaches. MedLion is another type of DPC network, with $>40$ practices across the United States, that claims its "largest client is a 100,000 member association, and its smallest has 3 parttime employees." 34 Paladina Health is a DPC practice operated by the DaVita Corporation with at least 37 clinics across 8 states, and they also are focused on marketing DPC services directly to employers. White Glove Health is an entity focusing on house calls performed by nurse practitioners and does not offer the full scope of primary care services; therefore it did not meet our definition of DPC. Brian Forrest, of Access Health Care, also has a network known as Access Health Care Direct, and AtlasMD sells a comprehensive software solution to DPC practices that includes many features often found in a network. 